\title{
Abdominal pain and vomiting in a paint stripper
}

\author{
General Medical Unit, \\ Royal Infirmary of \\ Edinburgh, Lauriston \\ Place, Edinburgh, UK \\ SP Hart \\ B McIver \\ BM Frier
}

Department of Public Health Sciences, University of Edinburgh Medical School, Teviot Place, Edinburgh, UK RM Agius

Correspondence to Dr SP Hart, Department of Diabetes, Royal Infirmary of Edinburgh, Lauriston Place, Edinburgh EH3 9YW, UK

Accepted 9 June 1995

\author{
Simon P Hart, Bryan McIver, Brian M Frier, Raymond M Agius
}

An 18-year-old man presented to the Accident and Emergency Department with a three-day history of central abdominal pain and vomiting, preceded by constipation and anorexia for one month. He gave no other medical history and was taking no medication. He had left school aged 16 to work for his self-employed father as a paint stripper and furniture restorer. This involved burning old paint from furniture and doors with a gas torch, sanding, and using chemicals to strip paint. He wore no personal protection other than a cloth tied over his nose and mouth. He ate meals and smoked while at work. Physical examination revealed slight conjunctival pallor and a diffusely tender abdomen without signs of peritonism. Digital rectal examination was normal. Plasma electrolytes, glucose, and amylase were within the normal ranges. Radiographs of the chest and abdomen showed no abnormality. The white cell count was $12 \times 10^{9} / 1$, haemoglobin concentration $11.7 \mathrm{~g} / \mathrm{dl}$ (mean corpuscular volume $81 \mathrm{fl}$, mean corpuscular haemoglobin $27.5 \mathrm{pg}$ ), and platelet count $306 \times 10^{9} / 1$. A photomicrograph of the peripheral blood film is shown below.

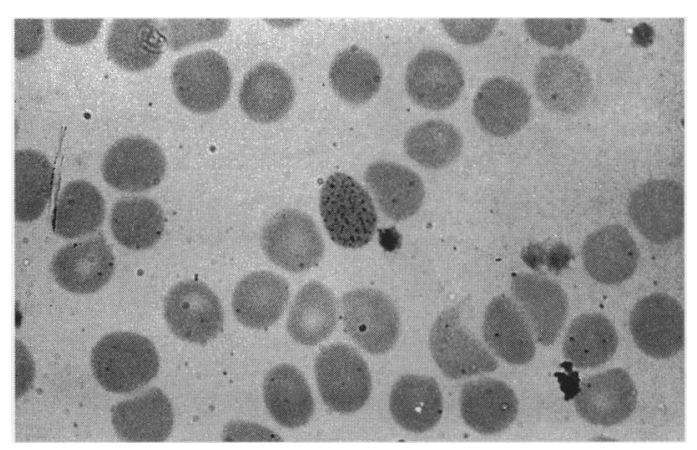

\section{Questions}

1 What abnormality is demonstrated on the blood film?

2 What is the likely diagnosis?

3 How can the diagnosis be confirmed?

4 What therapeutic options are available in the short term?

5 What long term measures should be instituted to prevent recurrence?

Figure Patient's peripheral blood film 
Answers

QUESTION 1

Basophilic stippling of erythrocytes.

QUESTION 2

Inorganic lead poisoning due to occupational exposure to lead paint.

\section{QUESTION 3}

A blood lead level, measured in whole blood by modern sensitive laboratory methods, is the definitive test of recent exposure to lead. Various 'biomarkers' of lead exposure are based on the inhibition of enzymes involved in the synthesis of haem, and subsequent accumulation of their substrates. Inhibition of aminolaevulinic acid dehydratase results in accumulation of 5-aminolaevulinic acid, which can be measured in the urine. Increased levels of erythrocyte zinc protoporphyrin reflect inhibition of haem synthetase.

\section{QUESTION 4}

Removal from lead exposure is essential. Administration of lead-chelating agents (table) results in the formation of water-soluble chelates and hence increased urinary lead excretion. They may be given to patients with lead poisoning who have symptoms associated with a high blood lead level. All of these drugs are potentially very toxic and should be given only under careful medical supervision.

\section{QUESTION 5}

Steps must be taken to reduce exposure to lead (box 1). In the present case this should include the use of local exhaust ventilation, appropriate respirators, and avoiding eating and smoking at the workplace. With the patient's consent the Health and Safety Executive should be contacted with a view to instituting regular surveillance, including monitoring of blood lead levels.

\section{Discussion}

In the present case the initial differential diagnosis included intestinal obstruction, acute appendicitis, and pancreatitis, and the opinion of a surgeon was sought. However, the correct diagnosis became apparent when the results of laboratory investigations were available. The patient had a microcytic anaemia and the blood film showed basophilic stippling of eryth-

Table Lead-chelating agents

\begin{tabular}{lll}
\hline Drug & $\begin{array}{l}\text { Mode of } \\
\text { administration }\end{array}$ & Comments \\
\hline Calcium edetate disodium & intravenous & $\begin{array}{l}\text { given alone or in combination } \\
\text { with dimercaprol }\end{array}$ \\
Dimercaprol & intramuscular & $\begin{array}{l}\text { given in combination with cal- } \\
\text { cium edetate disodium }\end{array}$ \\
Penicillamine & oral & -
\end{tabular}

Steps to reduce occupational exposure to lead

- substitute alternative agents, eg, titanium dioxide as a paint pigment

- segregate eating, smoking, resting, and non lead-related work from those tasks that contribute to lead exposure

- employ local exhaust ventilation to remove lead dust and fumes from the source and away from the workers' breathing zone

- wear well-fitted respirators with appropriate filters

Box 1

rocytes (see figure). The provisional diagnosis of inorganic lead poisoning was supported by a high blood lead level of $4.8 \mu \mathrm{mol} / 1$ (normal range $\quad 0.5-0.75 \mu \mathrm{mol} / \mathrm{l}$ ). Significant interference with haem synthesis was confirmed by demonstrating elevated urinary excretion of 5-aminolaevulinic acid ( $463 \mu \mathrm{mol} /$ $24 \mathrm{~h}$ ). Urinary porphobilinogen excretion was normal. He was treated with penicillamine by mouth resulting in complete resolution of his symptoms, a 60 -fold increase in urinary lead excretion, and a fall in blood lead level to $3.2 \mu \mathrm{mol} / 1$. With the patient's consent the Employment Medical Advisory Service of the Health and Safety Executive was informed, and he was discharged from hospital. During the period of the patient's inpatient treatment his 15-year-old brother was enlisted into the family business. The patient's father (aged 49) was asymptomatic but also had a microcytic anaemia with basophilic stippling of erythrocytes and a blood lead level of $5.2 \mu \mathrm{mol}$. He declined further investigation. Eight months later the patient consulted his general practitioner about an unrelated problem, and the opportunity was taken to send further blood samples for analysis from him and his father. Both had elevated blood lead levels of $3.1 \mu \mathrm{mol} /$ 1 and $3.9 \mu \mathrm{mol} / 1$, respectively, indicating the measures to reduce lead exposure either had not been implemented or were inadequate.

Lead is absorbed by inhalation and ingestion, and gradual accumulation of lead in the body leads to the clinical features of poisoning (box 2). In adults a blood lead level of less than $4 \mu \mathrm{mol} / 1$ is unlikely to be associated with features of chronic toxicity, but 'toxic' blood levels may not be associated with symptoms. ${ }^{1}$ White lead oxide ( $\mathrm{PbO}$ ) was first used as a pigment in paint in the late 19 th century, and in the same period public concern grew about occupational exposure to lead. Nowadays, lead poisoning is rare in developed countries as a result of improved industrial hygiene, legislation, and medical surveillance. ${ }^{2}$ True cases of lead toxicity may be considerably underdiagnosed. ${ }^{1}$

Lead poisoning is a preventable disease. The steps discussed above must be taken to reduce lead exposure. By law, according to the Control of Lead at Work Regulations in the UK, workers thought to be 'at risk' by virtue of their level of occupational exposure must have 


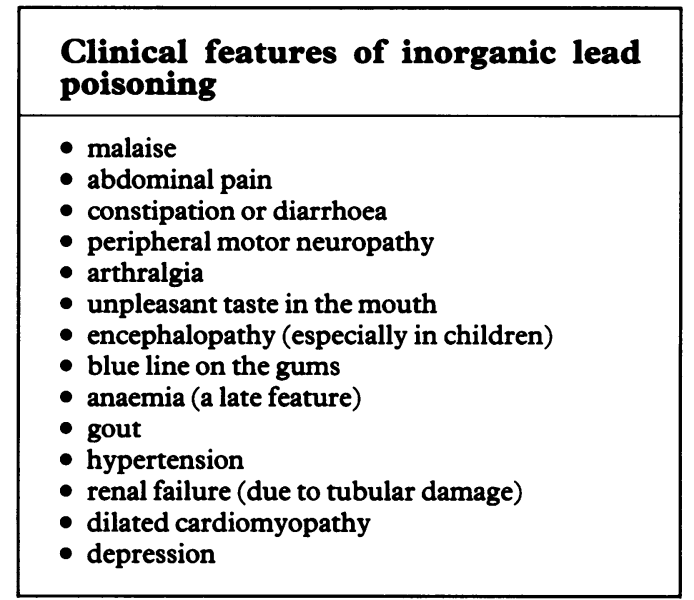

Box 2

regular health surveillance including monitoring of blood lead levels, in addition to other legal requirements for workplace assessment and control (box 1). If the blood lead level, usually when repeated, is $\geqslant 3.36 \mu \mathrm{mol} / 1$ the individual is certified as unfit for work that involves lead exposure, and must not resume work until the blood lead level is lowered. However, in small firms and self-employed workers such legal obligations are difficult to enforce. To our knowledge, the patient's father did not comply with the statutory requirements, and has ignored all advice from the Health and Safety Executive. We presume that the patient, his father, and possibly also his younger brother continue to be exposed to lead in toxic quantities through their working practice.

In the UK in 1991/92 there were 276 male workers with a reported blood lead level $\geqslant 3.36 \mu \mathrm{mol} / 1$ out of 23978 under surveillance, in compliance with the Control of Lead at

\footnotetext{
1 Rempel D. The lead-exposed worker. $\mathscr{f} A M A$ 1989; 262: 532-4.

2 Waldron HA, Scott A. Diseases associated with chemical agents:metals. In:Raffle PAB,Adams PH, BaxterPJ, LeeWR eds. Hunter's diseases of occupations 8th edn. London: Edward Arnold, 1994; pp 90-138.

3 Health and Safety Commission. Annual Report 1992/93. Statistical supplement. Sudbury: HSE Books, 1993

4 Frankel D. Global lead poisoning. Lancet 1994; 343: 787.

5 Marino PE, Landrigan PJ, Graef J, et al. A case report of lead paint poisoning during renovation of a Victorian farmhouse. Am F Public Health 1990; 80: 1183-5.
}

\section{Learning points}

- a detailed occupational history is an important part of the assessment of a patient

- lead poisoning still occurs, and it may be considerably underdiagnosed

Box 3

Work Regulations. ${ }^{3}$ The problem of lead poisoning from paint is likely to persist even where the use of lead paint for interior decoration has been banned ${ }^{4}$ because an important and often unrecognised hazard relates to paint strippers. There have been a few reports of lead poisoning associated with stripping paint. ${ }^{5,6}$ Workers and doctors are probably less aware of the hazards of lead toxicity associated with paint stripping than with the risks of other lead-exposed occupations such as involvement in the smelting and refining industries and working with lead batteries. The Employment Medical Advisory Service is available for information and advice about all such matters.

The present case demonstrates the importance of taking a full occupational history. Abdominal pain is a recognised manifestation of lead toxicity and it may present as a surgical emergency. 6,7 The correct diagnosis was not contemplated at first, but was suggested when the result of the blood film was obtained and the clinical history was carefully reviewed. Many more British workers may be at risk than are currently monitored by occupational health surveillance, ${ }^{8}$ and the true prevalence of lead poisoning may be higher than reported. ${ }^{2}$ The clinician should be careful to consider the relevance of the patient's occupation to the presenting symptoms.

6 Cullen MR, Robins JM, Eskenazi B. Adult inorganic lead intoxication: presentation of 31 new cases and a review of intoxication: presentation of 31 new cases and a review of 7 Esham RH, Sugg JH. Lead colic masquerading as intestinal Esham RH, Sugg JH. Lead colic masqueradin
obstruction. South Med $₹$ 1973; 66: 959-60.

8 Pagliuca A, Mufti GJ. Lead poisoning: an age-old problem $B M \mathcal{1 9 9 0 ;} 300: 830$. 